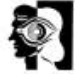

columns

\section{Ashley Robin}

Formerly Consultant Psychiatrist Runwell Hospital, Essex Charing Cross Hospital

Ashley Robin was born in 1925 in the East End of London and was raised in Greenford, attending Ealing Grammar School. He moved with his family to Glasgow at the age of 16, although he had cycled there by himself at 14 - an early demonstration of his determination, which remained throughout his life. He studied medicine at Glasgow University, where he graduated MBChB in 1947 and was awarded his MD in 1958. He began his career in psychiatry when he was 23 at Runwell Hospital, from 1950 to 1980 , where he eventually became consultant and sometime deputy physician superintendent. He gained the DPM in 1951 and was elected FRCPsych in 1972. His first mentor, James Valentine, considers him "one of the best", a phrase with which al who knew him would agree. He was an authority on the Mental Health Act and gave distinguished service as a medical member of the Mental Health Act Tribunal from 1960 until 1997, retiring at age 72. He took a scholarly approach to his subject and applied careful scientific method to his research, which was unusually prolific for a full-time consultant, with more than 45 research studies and articles published, mostly in the British Journal of Psychiatry.

Ashley rang me just after he had a serious heart attack while going to (and

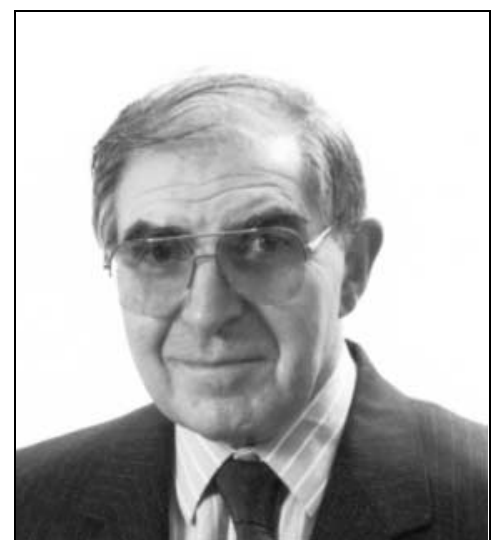

completing) interviews for a postretirement post at the Department of Health in 1980. He completed the interview and returned to his flat and rang me to take him to Charing Cross, although we had never met. After his coronary, I persuaded him to begin his second career at Charing Cross, where he became Head of the Gender Identity Unit, the largest in the world. He was, as well, a consultant to the Home Office, examining inmates at Pentonville Prison. This determination not to be daunted by health difficulties served him well for the succeeding 21 years, despite a coronary bypass in 1985 , and 10 years of increasing heart failure and Parkinson's disease.

His last contribution to medical knowledge was an analysis he and I made of the decline in admissions under the Mental Health Act through the 1970s until 1987, after which they steadily increased to previous 1970s levels. He noted that the change occurred when bed numbers crossed the point that Tooth and Brook, in 1972, predicted that bed numbers would meet need, following the discharge of the old long-stay from mental hospitals and their eventual closure. Tooth and Brook had not anticipated the zeal of managers and advocates of community care to shut down beds far beyond scientifically estimated predictions. Unfortunately, publication was rejected - we felt this was because the statement went against the rush to 'community care'.

Ashley courageously nursed his French wife, Monique, during her long illness with cancer and she died in 1992. He renewed his interest in bridge, and played 2-3 times a week in London and on holidays, often with his sister Jeannette in warmer parts of the world. In the last 2 or 3 years of his life he was increasingly handicapped by his Parkinsonism, yet travelled to Turkey just 4 months before his death, and played his last hand of bridge only a week before he died.

Ashley Robin engendered warm feelings; he had a wonderful dry humour and was a man of the highest principles, who was respected and appreciated by his professional colleagues, friends and family alike.

He leaves a son, Philip, a daughter, Jane, and four grandchildren whom he adored and of whom he was extremely proud.

\section{S. R. Hirsch}

\section{reading about}

\section{Self help books on pre- school parenting problems}

Books have had a dramatic impact on child rearing practices in past years. Benjamin Spock (1956), who produced the parent's bible of the post-war period, has been blamed for the permissive society and many other ills of the 60s generation, while Hugh Jolly (1975) recommended the 'family bed' and created a generation of confused parents. Penelope Leach's book (1979) was my first parenting text as a mother and she has now updated this into a 3rd edition (1997). Her writing is helpful and informative and presents the needs of the child as being paramount. She does help parents think about how to approach the problem rather than being rigid and dictatorial about how parents should behave.

Certain questions need to be considered when recommending books for parents:
- Do the parents want general advice about child rearing and parenting skills or do they have a child with a specific problem (Daws, 1989; Douglas \& Richman, 1984; Douglas, 1991; Haslam, 1995; Kitzinger, 1990)?

- Do they want reassurance or confirmation about what they are doing; quick tips on how to cope with simple everyday problems without bothering their general practitioner (GP); or detailed advice on how to cope with a more complex difficulty?

- Which style of book is most suited to the parent, i.e. magazine style with many illustrations and brief bites of information or non-pictorial, discursive and detailed?

The style of the author is an important consideration for parents to feel comfortable with the advice. Patronising writing can make parents feel inadequate or guilty and the clinical training or the therapeutic orientation of the author will affect how he or she writes. Authors may write primarily from the perspective of the child and try to enable parents to understand how the child perceives and reacts to the world. Others are humorous and try to lighten the anxiety and reassure parents. Some books oversimplify in an effort to normalise a problem or to generalise to as wide an audience as possible.

At present, books by Christopher Green, a paediatrician, seem to be highly in favour among GPs and health visitors. He started with Toddler Taming (Green, 1984) in the 1980s and has updated it for the 1990s (Green, 1992). He has a humorous relaxed style, which aims to be reassuring, using clinical experience and his own experience as a parent. However, it is a general book dealing with everyday mild behaviour problems and does not cover more severe behaviour problems in sufficient depth.

In his advice on managing sleep problems, I have always been concerned about his 'controlled crying' technique as it does not fit the pattern of standard behavioural management advice. It 